\title{
Multivariate analysis of predictive factors of multiple sclerosis course with a validated method to assess clinical events
}

\author{
M Trojano, C Avolio, C Manzari, A Calo', F De Robertis, G Serio, P Livrea
}

\begin{abstract}
The clinical data of 309 patients with definite multiple sclerosis were recorded in the European data base for multiple sclerosis (EDMUS) to determine the prognostic significance of several demographic and clinical variables. An interview with closed questions structured according to standardised criteria of disease phases and courses was used to assess the clinical course. The reliability was evaluated by four trained neurologists in a sample of 33 patients with multiple sclerosis. Both the within and between rater agreement on data collection was fair to high for the historical variables $(K=0 \cdot 33-1)$. Between rater agreement was more variable for the evaluation of 12 different EDMUS event categories $(K=0 \cdot 3-0 \cdot 95)$. The predictive model for the time to reach a secondary progression showed that an age at onset older than $25(p=0.006)$ and an event at onset followed by disability $\geqslant 3$ on the Kurtzke expanded disability status scale (EDSS; $p=0.004$ ) were the most unfavourable clinical variables in 249 patients with relapsing remitting $(180)$ or relapsing progressive (69) courses. In the 69 patients with relapsing progressive disease, the time to reach severe disability (EDSS $\geqslant 6$ ) was negatively influenced by a first interval between attacks shorter than one year, a number of bouts with EDSS $>2$ in the first two years of the disease, and involvement of the pyramidal system at onset $(p<0.05)$. In 60 patients with chronic progressive disease this outcome was negatively influenced by pyramidal, brainstem, and sensory involvement at onset $(p<0.01)$.
\end{abstract}

University of Bari, Italy, Institute of Clinical Neurology M Trojano

C Avolio

C Manzar

A Calo'

F De Robertis

$P$ Livrea

Institute of Hygiene G Serio

Correspondence to: Dr Maria Trojano, Institute of Clinical Neurology, University of Bari, Policlinico, Piazza Giulio Cesare, 70124 Bari, Italy.

Received 2 February 1994 and in final revised form

28 September 1994

Accepted 7 October 1994
(F Neurol Neurosurg Psychiatry 1995;58:300-306)

Keywords: multiple sclerosis; multivariate analysis; predictive factors

Clinical studies in multiple sclerosis are difficult to carry out because of the complex nature of a disease characterised by a mixture of acute and chronic aspects. In the past few years several studies have been performed to determine the prognostic value of demographic and early disease characteristics in patients with multiple sclerosis, but no reliable prognostic marker for individual patients has yet been convincingly identified. Female

sex has been associated with a more benign course in some studies ${ }^{14}$ and male sex in others ${ }^{5}$; other studies have failed to detect any correlation. ${ }^{7-9}$ Some, ${ }^{1410}$ but not all, ${ }^{6-911}$ investigators found a worse outcome in those patients with an older age of onset and a short first interval between attacks. ${ }^{12}$ The relapsing remitting disease course has been found to be more favourable than the chronic progressive course in most series. ${ }^{124-911} \mathrm{~A}$ high exacerbation rate seems to induce a worse prognosis in a few studies ${ }^{210}$ and only a few reports deal with the importance of a mild disability at five years. ${ }^{129-1113}$ More than one Kurtzke functional system ${ }^{14}$ involved at onset seems to be a factor in worse prognosis. ${ }^{11} \mathrm{~A}$ favourable prognosis when the presenting symptom is optic neuritis has been found by some ${ }^{2-10}$ but not all investigators. ${ }^{411}$ Similarly initial sensory symptoms have been considered favourable by some, ${ }^{110}$ but not by others. ${ }^{24811}$ The lack of uniformity of methods used in different studies to assess retrospective as well as prospective clinical events in multiple sclerosis is probably one of the major reasons for this controversy. Therefore, the use of a common language is an essential prerequisite to standardise morbidity records in patients with multiple sclerosis. In this paper we report the results of a multivariate survival analysis of predictive factors of long term disease course performed on clinical data from a hospital based series of 309 patients with definite multiple sclerosis recorded in the European data base for multiple sclerosis (EDMUS). ${ }^{15}$ An interview with closed questions structured according to standardised criteria of disease phases and courses ${ }^{16}$ was used to assess the chronology of clinical events in multiple sclerosis.

\section{Material and methods}

The clinical data of 380 outpatients with multiple sclerosis with onset of disease between 1976-91 were recorded in a data base prepared according to the EDMUS standardised form. Clear documentation of the early clinical course of these patients was available as they were followed up in our clinic yearly or half yearly from the onset of the disease by one of us (PL, MT, CA) with primary interests in multiple sclerosis. An interview with closed questions (fig 1), structured according to standardised criteria for disease phases, ${ }^{10}$ was used to assess retrospectively as well as prospectively the chronology of clinical events of patients with multiple sclerosis. By means 

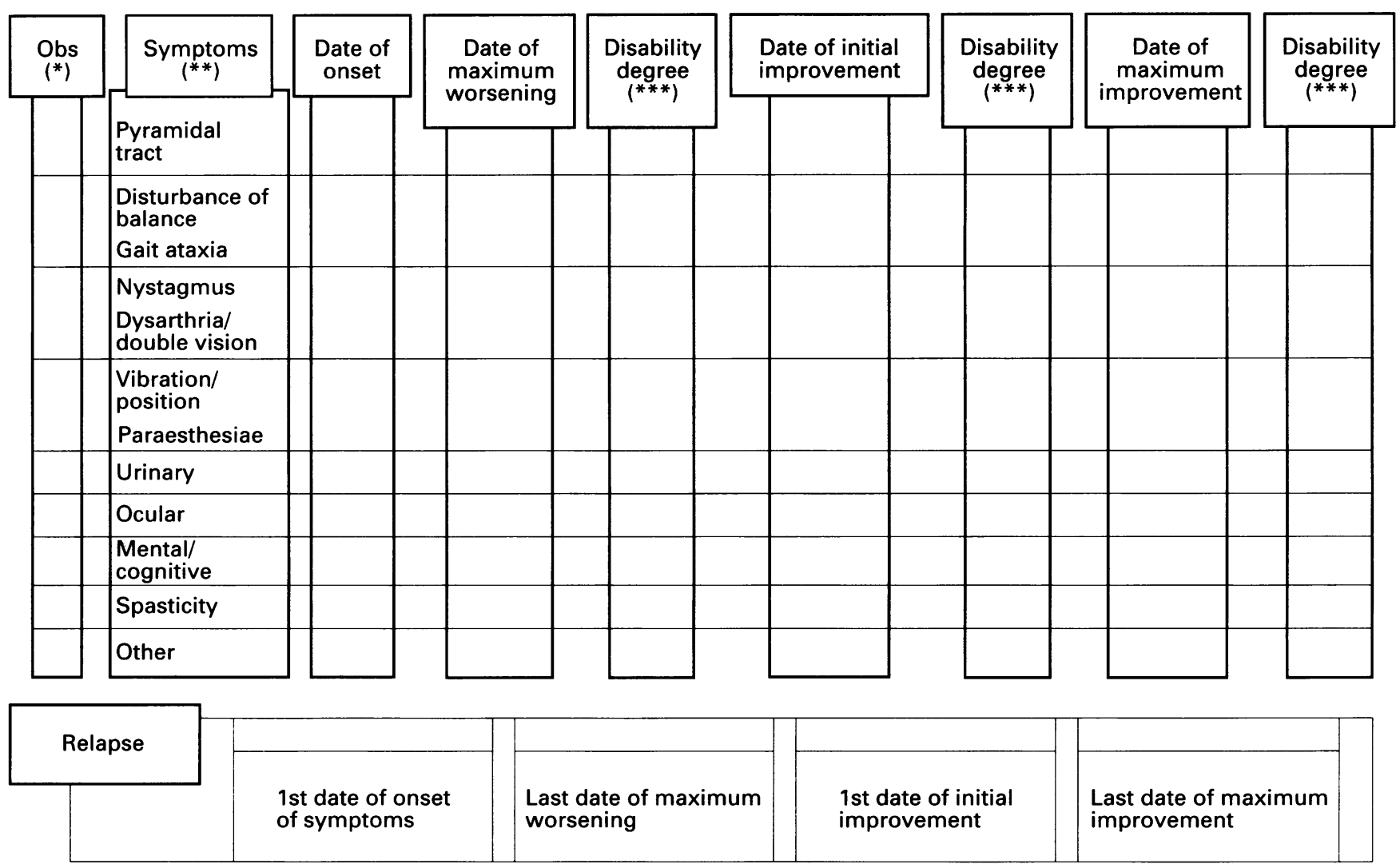

\begin{tabular}{|c|c|c|c|}
\hline $\begin{array}{l}\text { Duration: Worsening (days) } \\
\text { Inactivity Phase: Onset (day) }\end{array}$ & $\begin{array}{l}\text { Plateau (days) } \\
\text { End (day) }\end{array}$ & $\begin{array}{l}\text { Improvement (days) _ } \\
\text { Duration (days) _ }\end{array}$ & Relapse (days) _ \\
\hline
\end{tabular}

Figure 1 Interview with closed questions structured according to standardised criteria of disease phases and courses. ${ }^{16}\left({ }^{\star}\right)$ The column "OBS" (observations) was marked if symptom $(s)$ had been investigated by a neurologist and/or the related documentation was available. ( $\star *$ ) Symptoms to investigate were grouped in more frequent categories. Some categories of symptoms were grouped to agree with the Kurtzke functional systems. The evaluation of each symptom (lasting at least 24 hours) was investigated separately from all others present at the same time. ( $* *$ ) The patient disability status was stated by EDSS at the time of examination. For the disability evaluation at each follow up during the history we prepared a standardised form (available on request) by which it was possible to quantify retrospectively the severity of symptoms, graded according to the Kurtzke scale. Each functional system involvement was defined as mild, moderate, or severe assessing in each class a 2 point interval of the Kurtzke scoring system.

of reports provided by the patient and his relatives, and clinical records, each event was scored for symptoms, severity, dates of onset, maximum worsening, and initial and maximal improvement. Data were then available to measure the duration of each relapse, the different relapse phases (worsening, plateau, improvement), and the inactivity phases between the relapses.

Each clinical event was then classified as one of the 12 categories included in EDMUS. ${ }^{15}$ During the "no sequelae period" of the relapsing remitting course, a distinction was made between the relapse at onset (RO) and subsequent relapses with a complete remission and a well identified (RR) or an uncertain chronology (RU). During the "sequelae period" of the same course, a distinction was made between the relapse at onset (SO) and subsequent relapses with a well identified date of onset and followed by a non-worsening $(\mathrm{SN})$, or a worsening (SW), or a doubtful worsening (S?) of pre-existing sequelae and relapses with uncertain chronology (SU). During the "chronic progressive period", a distinction was made between onset without any initial relapse (POP) or with an inaugural relapse (POR) and subsequent relapses with a well identified (PR) or uncertain chronology (PU).

The disease course was defined as follows. A relapsing remitting course was defined as the occurrence of (a) phase(s) of worsening lasting less than six months followed by phase(s) of improvement or combined improvement and inactivity lasting at least one month; or (b) phase(s) of worsening lasting less than six months followed by a plateau phase lasting at least one year; or $(c)$ phases of worsening, each lasting less than six months and each having an onset after at least one month from the maximum worsening of the previous one; the maximum worsening of the last of such phases is reached before six months from the onset of the first one; and the last of such worsening phases is followed by a phase of improvement and inactivity lasting at least one month or by a plateau phase lasting at least one year. The chronic progressive course was defined as the occurrence of (a) a progressive worsening lasting more than six months from the disease onset; or (b) phases of worsening spaced by plateau phases lasting more than one month and less than one year; the last phase of worsening is still present or starts after six months from the disease onset. The relapsing progressive course was defined as a relapsing remitting course 
followed by one of the two options described for the chronic progressive course.

The patient's disability was derived from the Kurtzke expanded disability status scale $(\text { EDSS })^{14}$ at the time of examination, and it was also evaluated retrospectively for each visit during the history.

To evaluate the reliability of the clinical history, the standardised interview was initially given by PL, MT, CA, and FDR to a randomly selected sample of 33 patients with definite multiple sclerosis with disease duration ranging between two and 226 months, age between 18 and 52 years, and with an EDSS score between 0 and 7 ; no patients had objective signs of cognitive impairment as indicated by a mini mental state score ${ }^{17}$ higher than 24. All patients gave their informed consent. The between and within observer agreement rates ${ }^{18}$ were measured after one day and after one month on the main collected clinical data-namely, symptoms at onset and during the disease course, number of worsening and inactivity phases, current phase of the disease, diagnostic categories, duration of the first interval between attacks, and of the first inactivity phase. The between rater agreement on the definition of the 12 different EDMUS event types was also calculated in 21 out of 33 patients with definite multiple sclerosis. With the aforementioned procedure, 309 out of 380 outpatients with multiple sclerosis were found to fulfill the Poser criteria ${ }^{19}$ for definite multiple sclerosis (208 clinically definite of whom 159 belonged to $\mathrm{A} 1$ and 49 to A2 diagnostic categories, and 101 laboratory supported definite of whom two belonged to $\mathrm{B} 1$, 33 to $\mathrm{B} 2$, and 66 to $\mathrm{B} 3$ diagnostic categories). One hundred and eighty were classified, according to disease course, as relapsing remitting, 69 as relapsing progressive, and 60 as chronic progressive. The distribution according to sex showed a female/male ratio of $1 \cdot 3$. The mean age at onset was 26 (SD 8) years; the mean disease duration and the mean EDSS score were respectively 9.8 years and $3 \cdot 7$, with a yearly mean increase in disability (progression index) of $0 \cdot 66$. Forty two per cent of patients had mild (EDSS $0-2 \cdot 5$ ), $37 \%$ moderate (EDSS $3-5 \cdot 5$ ), and $21 \%$ severe disability (EDSS 6-9). The percentage of patients with severe disability increased from $6 \%$ at less than five years to $38 \%$ at

Table 1 Clinical and demographic characteristics in 309 patients with definite multiple sclerosis with different disease course

\begin{tabular}{|c|c|c|c|}
\hline & \multicolumn{3}{|l|}{ Disease course } \\
\hline & $\begin{array}{l}\text { Relapsing } \\
\text { Remitting } \\
(R R) \\
(n=180)\end{array}$ & $\begin{array}{l}\text { Relapsing } \\
\text { Progressive } \\
(R P) \\
(n=69)\end{array}$ & $\begin{array}{l}\text { Chronic } \\
\text { Progressive } \\
(C P) \\
(n=60)\end{array}$ \\
\hline $\begin{array}{l}\text { Female/male (sex ratio) } \\
\% \text { Of event at onset } \\
\text { with sequelae }\end{array}$ & $\begin{array}{c}107 / 73 \\
16 \cdot 3^{\star}\end{array}(1 \cdot 47)$ & $\begin{array}{l}33 / 36(0.92) \\
32 \cdot 3\end{array}$ & $\frac{34 / 26(1 \cdot 3)}{-}$ \\
\hline $\begin{array}{l}\text { Age at onset (mean (SD)) } \\
\text { EDSS score (mean (SD)) }\end{array}$ & $\begin{array}{l}24(7 \cdot 7) \dagger \\
2 \cdot 3(1 \cdot 3) \ddagger\end{array}$ & $\begin{array}{r}27(8 \cdot 3) \dagger \\
5 \cdot 4(1 \cdot 5)\end{array}$ & $\begin{array}{l}31(8 \cdot 3) t \\
5 \cdot 6(1 \cdot 5)\end{array}$ \\
\hline $\begin{array}{l}\text { Disease duration } \\
\quad((\mathrm{y}) \text { mean }(\mathrm{SD}))\end{array}$ & $7 \cdot 3(5 \cdot 5) \oint$ & $14 \cdot 3(8 \cdot 6)$ & $12(7 \cdot 9)$ \\
\hline
\end{tabular}

${ }^{\star} \chi^{2}=7, \mathrm{p}<0.01 ; \dagger F=17.138, \mathrm{p}<0.0001 ; \ddagger F=210.6, \mathrm{p}<0.0001$ (RR $v \mathrm{RP}$ and $\left.\mathrm{CP}\right)$; $\int F=29.963, \mathrm{p}<0.0001$ (RR $v$ RP and CP). more than 10 years of disease duration. The prognostic significance of a number of demographic and initial clinical variables was evaluated in this multiple sclerosis cohort, accounting for the different types of disease course. The time from onset of multiple sclerosis to a secondary progression and time to severe disability (EDSS $\geqslant 6$ ) were used as end points.

\section{STATISTICAL ANALYSIS}

$\mathrm{K}$ statistics was used to measure the within and between observer agreement rate on clinical data collection.

Differences in the mean values and frequencies of the studied variables between patient groups stratified for disease course were examined by one way analysis of variance, Fisher's exact test, and $\chi^{2}$ test. A Weibull survival model (SAS statistical package) was used to assess the significance of several variables associated with outcomes. Differences between the survival curves (Kaplan-Meyer) were tested with log rank and Wilcoxon statistics.

\section{Results}

The reliability of the clinical records obtained by the combined use of the standardised interview and the EDMUS chronology form was satisfactory. ${ }^{20}$ An almost perfect between/within observer agreement $(K=1)$ was obtained on the definition of the diagnostic categories. ${ }^{18}$ A moderate to substantial $(\mathrm{K}=0.53-0.8 \mathrm{p}<0.0001)$ between observer and a fair to substantial $(K=0.33-0.8 \mathrm{p}=$ 0.001 to $<0.0001$ ) within observer agreement was found for the other historical variables considered. At the same time an overall moderate between rater agreement ( $\%$ of agreement $=62 / 130 ; \mathrm{K}=0.52 \mathrm{p}<0.0001)$ was found for the evaluation of the 12 different disease event categories. The agreement was almost perfect $(K=0.95 \mathrm{p}<0.0001)$ for $\mathrm{RO}$, substantial $(K=0.6-0.7 \mathrm{p}<0.0001)$ for $R R$ and $P R$, moderate $(K=0.4-0.5 p<0.0001)$ for SO, SN, and POP, and fair $(\mathrm{K}=0 \cdot 3-0 \cdot 4$ $\mathrm{p}<0.01)$ for $S W$ and $S$ ? events. Relapses with uncertain chronology in the three different course periods (RU, SU, PU) were not found. Table 1 shows the major differences in early clinical and demographic features found among the three subgroups of patients with different disease course. The distribution of disability score adjusted for duration of disease in these three subgroups showed (fig 2) that the relapsing remitting group was characterised by a significantly (Fisher's exact test, $\mathrm{p}<0.0001$ ) higher frequency of a mild disability and a lower frequency of severe disability than the relapsing progressive and chronic progressive groups. This was irrespective of whether patients had a duration of disease less than five years, between five and 10 years, or more than 10 years. For the distribution of functional systems involved at the onset of the disease (fig 3), the chronic progressive course was characterised by a significantly higher frequency of pyramidal (84\%), mental (13\%), 


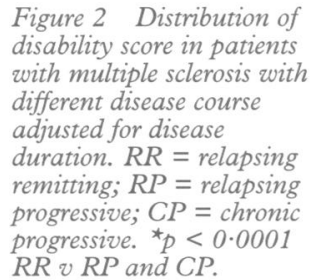

$R R v R P$ and $C P$.
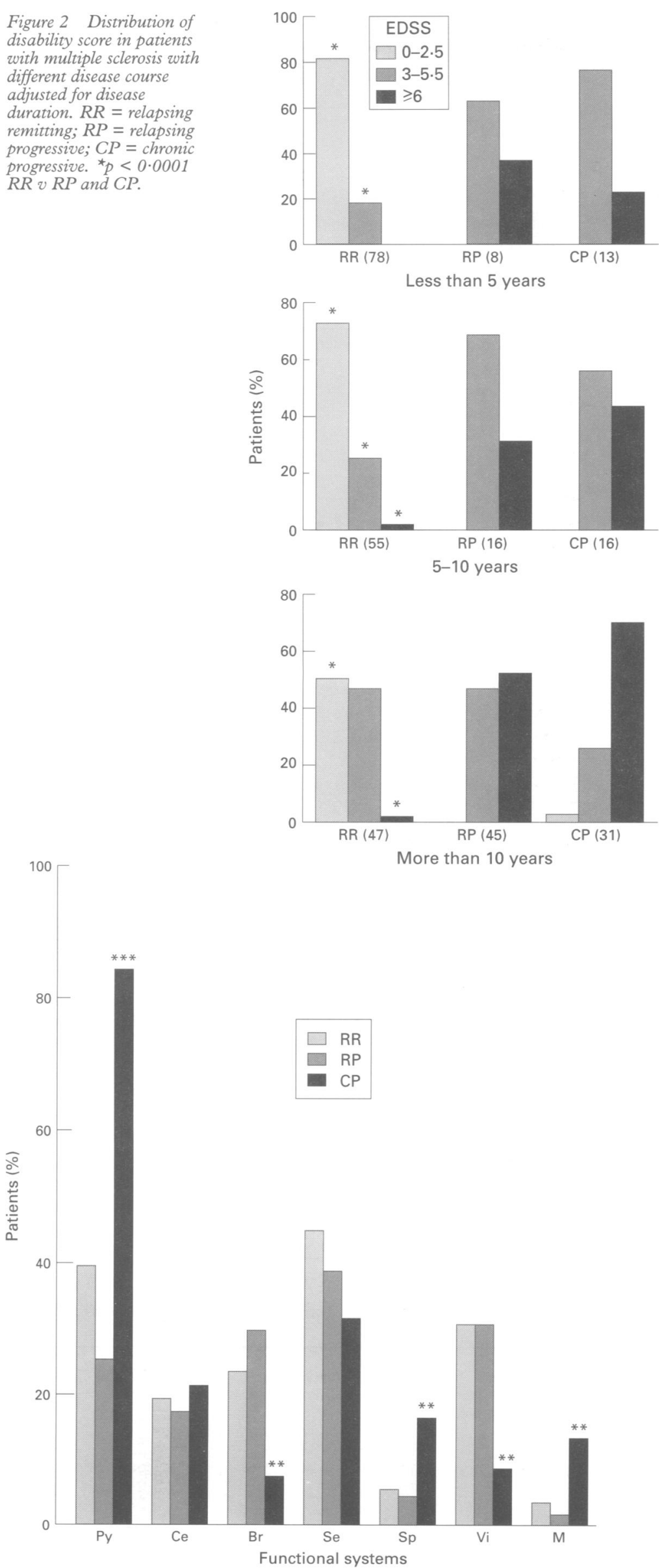

Figure 3 Frequency of functional systems involved at onset in 309 patients with multiple sclerosis adjusted for disease course. $P y=$ pyramidal; $\mathrm{Ce}=$ cerebellar; $\mathrm{Br}=$ brainstem; $S e=$ sensitive; $S p=$ sphincteric; $V i=$ visual; $M=$ mental; $R R=$ relapsing remitting; $R P=$ relapsing progressive; $C P=$ chronic progressive. ${ }^{\star *} p<0.01 ; * \star x p 0.001 C P v R R$ and $R P$. and sphincteric (16\%) symptoms and a lower frequency of brainstem $(7 \%)$ and visual $(8 \%)$ involvement than relapsing remitting and relapsing progressive courses. The predictive value of the aforementioned variables for the time to reach secondary progression was evaluated in the relapsing remitting and relapsing progressive groups together. The multivariate predictive model (table 2) showed that, despite the great number of censored patients $(72 \%)$, an age at onset older than 25 years $(p=0.006)$ and an event at onset with sequelae $(p=0.04)$ seemed the most unfavourable clinical variables. Figure 4 gives the survival curves showing the probability of patients not having reached progression after stratification according to age at onset older or younger than 25 years and the presence or absence of a disease event at onset with sequelae. The greatest differences were found in the groups with age at onset less than 25 years with or without sequelae after the event at onset (A and B) compared with the group with age of onset more than 25 years and sequelae (D). When the time to reach EDSS 6 was considered as the end point, relapsing progressive and chronic progressive groups were analysed separately because of the significant difference in survival curves (fig 5). These showed that a higher percentage of patients with relapsing progressive multiple sclerosis than those with chronic progressive multiple sclerosis had not reached this disability stage during the follow up time $(\log$ rank $\mathrm{p}=0.02$; Wilcoxon $\mathrm{p}=$ 0.02 ). In relapsing progressive disease, the multivariate predictive model showed (table 3) that an interval between first attacks shorter than one year, a number of bouts higher than 2 in the first two years of the disease, and a pyramidal involvement at onset reduced the time to severe disability significantly $(p<0.05)$. In the chronic progressive group (table 4) the involvement of pyramidal, brainstem, and sensory systems at the onset of disease were significantly $(p<0.01)$ associated with the same adverse outcome.

\section{Discussion}

These data show that the combined use of a standardised interview structured according to definite criteria for temporal limits of disease phases and courses ${ }^{16}$ and a precise classification of disease events such as proposed in the EDMUS ${ }^{15}$ allows us to obtain a good within and between observer agreement in collection of historical multiple sclerosis data. More than 100 clinical events were scored and for all of them the $K$ index was good. Relapses without sequelae were recognised with a high degree of agreement, both when occurring at the onset (RO) or during the disease course itself (RR); when the relapses were followed by sequelae (SO, SN) the agreement was still significant, but less so, particularly in the case of relapse with worsening (SW) and relapse with doubtful worsening (S?); relapses were well identified also when superimposed during the progressive course (PR). It is worthwhile noting that relapses 
Table 2 Multivariate analysis predicting the time to reach secondary progression in 249 patients with definite multiple sclerosis with relapsing remitting (180) and relapsing progressive (69) course (Lifereg Procedure SAS)

\begin{tabular}{|c|c|c|c|c|}
\hline Variable & Coefficient & $\begin{array}{l}\text { Standard } \\
\text { error }\end{array}$ & $\chi^{2}$ & p Value \\
\hline Male sex & $-0 \cdot 11$ & $0 \cdot 2$ & $0 \cdot 3$ & 0.6 \\
\hline No of FS at onset $(1$ or $>1)$ & 0.19 & 0.4 & $0 \cdot 2$ & 0.7 \\
\hline Age at onset $(<$ or $>25$ y) & -0.55 & 0.2 & $7 \cdot 3$ & 0.006 \\
\hline Disease event at onset with sequelae & -0.5 & $0 \cdot 2$ & 4 & 0.04 \\
\hline First interattack interval $(<$ or $>1 \mathrm{y})$ & 0.3 & 0.3 & $1 \cdot 3$ & 0.3 \\
\hline No of attacks in the first two years $(<$ or $>2)$ & -0.03 & $0 \cdot 3$ & 0.01 & 0.9 \\
\hline Pyramidal (at onset) & 0.25 & 0.35 & 0.5 & 0.5 \\
\hline Cerebellar (at onset) & 0.008 & 0.35 & 0.001 & 0.98 \\
\hline Sensitive (at onset) & -0.33 & 0.3 & $1 \cdot 2$ & 0.3 \\
\hline Sphincteric (at onset) & $-0 \cdot 1$ & 0.5 & 0.05 & 0.8 \\
\hline Brainstem (at onset) & -0.36 & 0.3 & 1.5 & $0 \cdot 2$ \\
\hline Visual (at onset) & 0.4 & 0.4 & 0.9 & 0.3 \\
\hline Intercept & $5 \cdot 8$ & 0.4 & $208 \cdot 9$ & 0.0001 \\
\hline
\end{tabular}

Weibull scale parameter $=0.76(0 \cdot 08) ; \%$ censored cases $=72 ; \mathrm{FS}=$ functional systems.

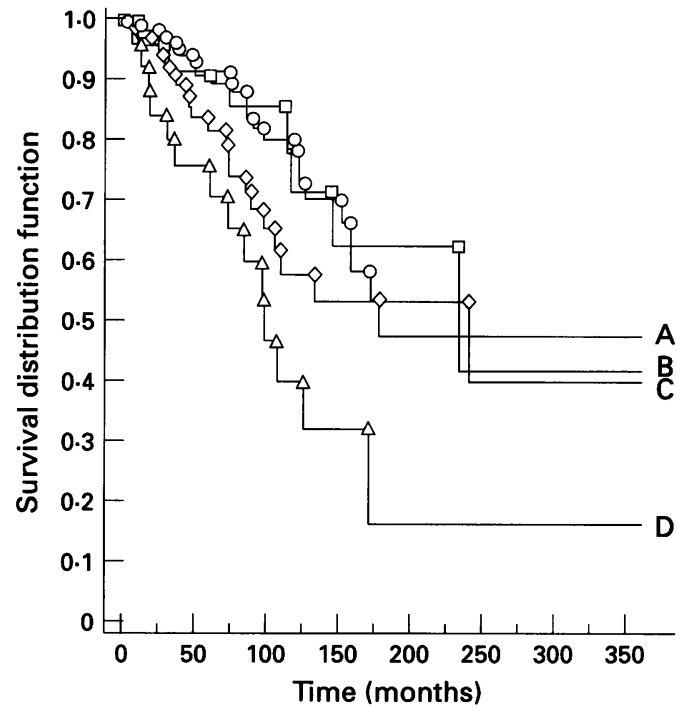

Figure 4 Survival probability of patients not having reached progression after stratification according to the age at onset and to the presence of a first disease event with sequelae. $A=$ age at onset $\leqslant 25 y$; disease event at onset without sequelae; $B=$ age at onset $\leqslant 25 y$; disease event at onset with sequelae; $C=$ age at onset $>25 y$; disease event at onset without sequelae; $D=$ age at onset $>25 y$; disease event at onset with sequelae. $p<0.001 A v D ; p<0.02$ $B v D$

Log rank

Wilcoxon

\begin{tabular}{lll}
$\chi^{2}$ & $D f$ & $p$ Value \\
\hline 13.6 & 3 & 0.004 \\
13.3 & 3 & 0.004
\end{tabular}

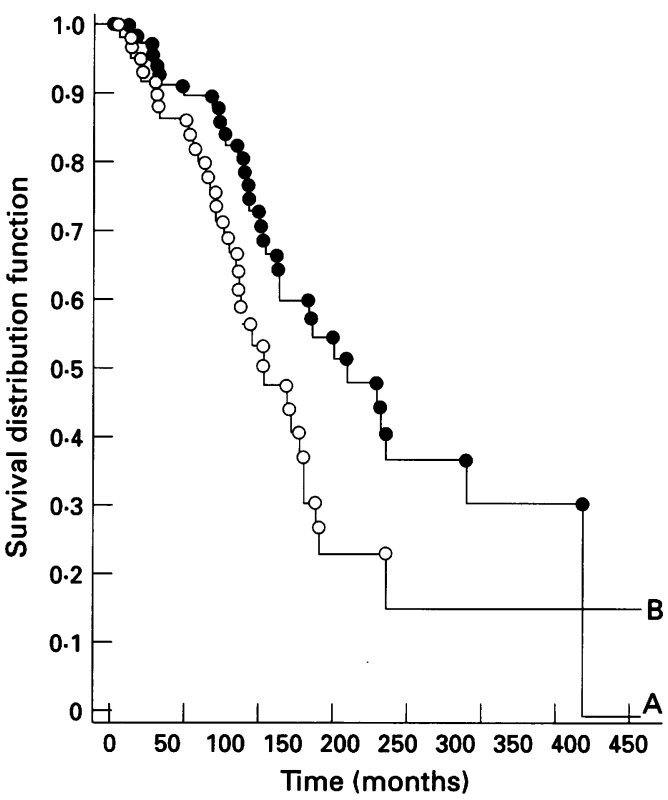

Figure 5 Survival probability of patients not having reached EDSS 6 after stratification according to chronic (60) or relapsing progressive (69) course; $A=$ relapsing progressive course; $B=$ chronic progressive course.

\begin{tabular}{lll}
$\chi^{2}$ & Df & $p$ Value \\
\hline $5 \cdot 19$ & 1 & 0.02 \\
$5 \cdot 13$ & 1 & 0.02
\end{tabular}

Log rank

Wilcoxon

Table 3 Multivariate analysis predicting the time to reach EDSS 6 in 69 patients with definite multiple sclerosis with relapsing progressive course (Lifereg Procedure SAS)

\begin{tabular}{|c|c|c|c|c|}
\hline Variable & Coefficient & $\begin{array}{l}\text { Standard } \\
\text { error }\end{array}$ & $\chi^{2}$ & p Value \\
\hline $\begin{array}{l}\text { Male sex } \\
\text { No of FS at onset }(1 \text { or }>1) \\
\text { Age at onset }(\leqslant \text { or }>25 \text { y) } \\
\text { Disease event at onset with sequelae } \\
\text { First interattack interval ( } \leqslant \text { or }>1 \text { y) } \\
\text { No of attacks in the first two years }(\leqslant \text { or }>2 \text { ) } \\
\text { Pyramidal (at onset) } \\
\text { Cerebellar (at onset) } \\
\text { Sensitive (at onset) } \\
\text { Sphincteric (at onset) } \\
\text { Brainstem (at onset) } \\
\text { Visual (at onset) } \\
\text { Intercept }\end{array}$ & $\begin{array}{r}-0.4 \\
0.6 \\
0.02 \\
-0.3 \\
0.5 \\
-0.8 \\
-1 \cdot 1 \\
0.5 \\
0.1 \\
0 \cdot 2 \\
-0 \cdot 1 \\
-0.4 \\
5 \cdot 1\end{array}$ & $\begin{array}{l}0.2 \\
0.5 \\
0.02 \\
0.3 \\
0.3 \\
0.3 \\
0.5 \\
0.4 \\
0.4 \\
0.5 \\
0.5 \\
0 \cdot 6 \\
0.6\end{array}$ & $\begin{array}{l}2 \cdot 8 \\
1 \cdot 2 \\
1 \cdot 1 \\
1 \cdot 2 \\
4 \cdot 5 \\
5 \cdot 3 \\
4 \cdot 5 \\
1 \cdot 6 \\
0 \cdot 1 \\
0 \cdot 1 \\
0 \cdot 1 \\
0 \cdot 33 \\
72 \cdot 5\end{array}$ & $\begin{array}{l}0 \cdot 1 \\
0 \cdot 3 \\
0 \cdot 3 \\
0 \cdot 3 \\
0 \cdot 03 \\
0 \cdot 02 \\
0 \cdot 03 \\
0 \cdot 2 \\
0 \cdot 8 \\
0 \cdot 7 \\
0 \cdot 7 \\
0 \cdot 6 \\
0 \cdot 0001\end{array}$ \\
\hline
\end{tabular}

Weibull scale parameter $=0.5(0 \cdot 07) ; \%$ censored cases $=54$. 
Table 4 Multivariate analysis predicting the time to reach a EDSS 6 in 60 patients with definite multiple sclerosis with chronic progressive course (Lifereg Procedure SAS)

\begin{tabular}{|c|c|c|c|c|}
\hline Variable & Coefficient & $\begin{array}{l}\text { Standard } \\
\text { error }\end{array}$ & $\chi^{2}$ & $p$ Value \\
\hline $\begin{array}{l}\text { Male sex } \\
\text { No of FS at onset }(1 \text { or }>1) \\
\text { Age at onset ( } \leqslant \text { or }>25 \text { y) } \\
\text { Pyramidal (at onset) } \\
\text { Cerebellar (at onset) } \\
\text { Sensitive (at onset) } \\
\text { Sphincteric (at onset) } \\
\text { Brainstem (at onset) } \\
\text { Visual (at onset) } \\
\text { Incercept }\end{array}$ & $\begin{array}{l}-0.01 \\
0.6 \\
-0.001 \\
-0.7 \\
-0.3 \\
-0.8 \\
-0.2 \\
-1.1 \\
-0.4 \\
5.8\end{array}$ & $\begin{array}{l}0 \cdot 2 \\
0 \cdot 3 \\
0 \cdot 01 \\
0 \cdot 3 \\
0 \cdot 3 \\
0 \cdot 3 \\
0 \cdot 3 \\
0 \cdot 4 \\
0 \cdot 4 \\
0 \cdot 5\end{array}$ & $\begin{array}{l}0 \cdot 003 \\
3 \cdot 3 \\
0 \cdot 003 \\
5 \cdot 4 \\
1 \cdot 4 \\
7 \cdot 8 \\
0 \cdot 3 \\
8 \cdot 6 \\
1 \cdot 3 \\
141 \cdot 8\end{array}$ & $\begin{array}{l}0.96 \\
0.07 \\
0.96 \\
0.02 \\
0 \cdot 2 \\
0.005 \\
0.6 \\
0.003 \\
0.3 \\
0.0001\end{array}$ \\
\hline
\end{tabular}

Weibull scale parameter $=0.5(0 \cdot 08) ; \%$ censored cases $=46$.

with "uncertain chronology" (RU, SU, PU) during the three different course periods ("no sequelae", "sequelae" and "chronic progressive") were not found in this series by standardised retrospective assessment of clinical history. The present historical-prospective study provides prognosis data only on a hospital based cohort of patients with definite multiple sclerosis, all recorded in the same centre by a validated methodology. Diagnostic criteria, different disease courses, and phases were well defined according to the panels of Poser et $a l^{19}$ and Schumacher et al. ${ }^{16}$ Most findings in our population are in accordance with other studies. The sex ratio, the age at onset, the progression index, and the patterns of clinical presentation were typical. The percentages of patients with chronic progressive and relapsing progressive courses were similar to the range of values ( $8-33 \%)$ reported by other authors. ${ }^{151012} 21-24$ The cross sectional distribution of disability on the Kurtzke scale showed a trend towards a bimodal distribution already noted ${ }^{7324}$ with peaks at EDSS 2 and EDSS 6 . This seems consistent with the difference in the time that patients spent at different EDSS levels ${ }^{25}$ : this was longest at EDSS 1-2, it was shortest at EDSS 4 and 5, and substantially longer at EDSS 6. Our results confirm that patients with multiple sclerosis with different disease courses show many clinical differences. Both relapsing progressive and chronic progressive forms, according to most reports, tended to occur at a later age ${ }^{2326}$ and showed a worse prognosis in terms of disability than the relapsing remitting form. ${ }^{71326}$ Indeed $46 \%$ of patients with the relapsing progressive and $53 \%$ of patients with the chronic progressive forms, but only $2 \%$ of patients with the relapsing remitting form showed severe disability 10 years from onset. In the chronic progressive group the most common mode of disease presentation was a progressive pyramidal involvement; moreover a greater frequency of mental and sphincteric, and a lesser frequency of visual and brainstem symptoms at onset were associated with this course by contrast with the relapsing remitting course. ${ }^{2324}$ Except for a trend towards fewer females in the relapsing progressive group no other significant influences of the patient's sex on the prognosis were found in this series; results found previously by many others. ${ }^{132227}$ The prognostic significance of the variables was weighted, as recently proposed, ${ }^{28}$ by a multivariate approach that allows the evaluation of the independent contribution of prognostic indicators by holding the effect of other indicators. The most predictive variables for a rapid shift to a secondary progression were an age at onset greater than 25 years, and then a disease event at onset with sequelae. The association of worse prognosis with an older age at onset, has been noted by most authors ${ }^{1} 121326-29$ with the principal difference between patients younger than and older than 40 years at onset. ${ }^{132930}$ This age related difference in the prognosis may just be a function of ageing as seen, for example, in the context of cerebrovascular disease or it may reflect age related changes in the immune response. ${ }^{30}$ Few studies deal with the prognostic value of residual score on EDSS at the first bout; it was found, nevertheless, to be a predictor of a secondary progression ${ }^{31}$ as in our series, but no relations between this residual invalidity and disability score at $10-15$ years were found. ${ }^{11}$ Significant differences in survival curves of disability between patients with chronic progressive and relapsing progressive forms were found in this study. There are other data indicating that chronic progressive and relapsing progressive forms of multiple sclerosis may be separate disease entities. They differ, for example, with respect to epidemiology ${ }^{32}$; recent analysis of HLA DR and DQ genes by restriction fragment length polymorphism has suggested that chronic progressive multiple sclerosis may be associated with a specific heterozygous Taq 1 HLA DQ $\beta$ restriction fragment, which is not seen in relapsing progressive multiple sclerosis ${ }^{33}$; differences in the pattern, extent, and dynamics of abnormalities on cerebral MRI between the two groups have been recently shown. ${ }^{34}$ Therefore, different predictive models for the time to reach EDSS 6 were generated for the two different kinds of progression. The age at onset seemed to be without significant predictive value on the time for a severe disability when a progressive course, either chronic progressive or relapsing progressive, was present. This shows that clinical course and age at onset probably have separate effects on disability. This has also been found by others. ${ }^{11} 26$ The occurrence of a remitting as well as progressive pyramidal involvement at onset seemed to be associated with a poor prognosis in both groups according to most 
reports, ${ }^{911} 13232635$ whereas initial brainstem and sensory symptoms were unfavourable only in the chronic progressive group. In patients with relapsing progressive multiple sclerosis a short first interval between attacks, and a high number of bouts in the first two years were also found to shorten the time to reach severe disability. An inverse relation between prognosis and the first interval between attacks as noted in the present sample has also been found by others. ${ }^{211122335}$ Confavreux $e t a l^{12}$ found a mean interval of 0.9 years in patients with a severe prognosis and in hyperacute cases; by contrast, the mean interval was 2.4 years in acute and 5.6 years in benign cases. Phadke showed that only one third of patients in the benign category had their first relapse in less than one year compared with $70.9 \%$ of those in the hyperacute prognostic category and $44 \%$ of those in the acute prognostic category. ${ }^{23}$ Many studies, however, have failed to document any relation between the number of attacks in the early years of multiple sclerosis and outcome..$^{811}$

In conclusion, our study corroborates the findings of others that many clinical and demographic factors are associated with outcome, but it also suggests different predictive models for patients with multiple sclerosis with different disease courses that could be useful in the selection of patients for clinical trials at an earlier point in the disease. The current availability of the EDMUS computerised programs will make it easier to follow up a large patient population from different geographical areas, scored by the same methodology so as to confirm these results by accurate and reliable data exchange and pooling.

We are grateful to Professor C Confavreux and Dr B G Weinshenker for helpful criticism of the manuscript. We thank Mr Brian Molloy for his assistance in revising the manuscript. This work has been supported by CNR grant No 9104185 and This work has been supported by CNR grant No 9104185 and DGX11 (contract No BMHI-CT93-1529).

1 Muller R. Studies on disseminated sclerosis with special reference to symptomatology, course and prognosis.
Acta Medica Scandinavica 1949;222(suppl):1-214.

2 Weinshenker BG, Bass B, Rice GPA, et al. The natural history of multiple sclerosis: a geographically based study. II. Predictive value of the early clinical course. Brain 1989;112:1419-28.

3 Broman T, Andersen O, Bergmann L. Clinical studies on multiple sclerosis. 1. Presentation of an incidence material from Gothenburg. Acta Neurologica Scandinavica 1981;63:6-33.

4 Wolfson C, Confavreux C. Improvements to a simple Markov model of the natural history of multiple sclerosis. Neuroepidemiology 1987;6:101-15.

5 Leibowitz U, Alter M, Halpern L. Clinical studies of multiple sclerosis in Israel. 3. Clinical course and prognosis tiple sclerosis in Israel. 3 . Clinical course and pro

6 Minderhoud JM, Van Der Hoevem JH, Prange AJA. Course and prognosis of chronic progressive multiple Course and prognosis of chronic progre

7 Goodkin DE, Hertsgaard D, Rudick RA. Exacerbation rates and adherence to disease type in a prospectively followed-up population with multiple sclerosis: Implications for clinical trials. Arch Neurol 1989;46: 1107-12.

8 Fog T, Linnemann F. The course of multiple sclerosis in 73 cases with computer-designed curves. Acta Neurol Scand Suppl 1970;47:11-175.
9 McAlpine $\mathrm{D}$. The benign form of multiple sclerosis. A study based on 241 cases seen within three years of onset and followed up until the tenth year or more of the disand followed up until the ten

10 McAlpine D, Compston N. Some aspects of the natural history of disseminated sclerosis. Part 1 . The incidence, history of disseminated sclerosis. Part 1 . The incidence, of course. $Q \mathcal{F}$ Med 1952;21:135-60.

11 Kurtzke JF, Beebe GW, Nagler B, Kruland L, Auth TL. Studies on the natural history of multiple sclerosis-8. Early prognostic features of the later course of the illness. Fournal of Chronic Diseases 1977;30:819-30.

12 Confavreux C, Aimard G, Devic M. Course and prognosis of multiple sclerosis assessed by the computerized data processing of 349 patients. Brain 1980;103:281-300.

13 Miller DH, Hornabrook RW, Purdie G. The natural history of multiple sclerosis: a regional study with some longitudinal data. $\mathcal{F}$ Neurol Neurosurg Psychiatry 1992;55: 341-6.

14 Kurtzke JF. Rating neurologic impairment in multiple sclerosis: an expanded disability status scale (EDSS). sclerosis: an expanded disabilit

15 Confavreux C, Compston DAS, Hommes OR, McDonald WI, Thompson AJ. EDMUS, a European database for multiple sclerosis. $\mathcal{F}$ Neurol Neurosurg Psychiatry 1992;55: 671-6.

16 Schumacher GA, Beebe G, Kibler RF, et al. Problems of experimental trials of therapy in multiple sclerosis: report by the panel on the evaluation of experimental trials of therapy in multiple sclerosis. Ann NY Acad Sci 1965;122:552-68.

17 Folstein MF, Folstein SE, McHugh PR. "Mini mental state": a practical method for grading the cognitive state of patients for the clinician. F Psychol Res 1975;12: 189-98.

18 Fleiss JL: Statistical methods for rates and proportions. 2nd ed. 2. New York: John Wiley and Sons, 1981:212-36.

19 Poser CM, Paty DW, Scheinberg L. New diagnostic criteria for multiple sclerosis: guidelines for research protoria for multiple sclerosis: guidelines

20 Landis JR, Kock GG. Measurement for observer agreement for categorical data. Biometrics 1977;33:159-74

21 Kurtzke JF, Park CS, Oh SJ. Multiple sclerosis in Korea: clinical features and prevalence. $\mathcal{F}$ Neurol Sci 1968; 6:463-81.

22 Panelius M. Studies on epidemiological, clinical and etiological aspects of multiple sclerosis. Acta Neurol Scand 1969; (suppl 39) 45:1-82.

23 Phadke JG. Clinical aspects of multiple sclerosis in northeast Scotland with particular reference to its course and prognosis. Brain 1990;113:1597-1628.

24 Weinshenker BG, Bass B, Rice GPA, et al. The natural history of multiple sclerosis: a geographically based history of multiple sclerosis: a geographically based
study. I. Clinical course and disability. Brain 1989; study. I. C

25 Weinshenker BG, Rice GPA, Noseworthy JH, Carriere W, Baskerville J, Ebers GC. The natural history of multiple sclerosis: a geographically based study. IV. Applications to planning and interpretation of clinical therapeutic trials. Brain 1991;114:1057-67.

26 Riise T, Gronning M, Fernandez O, Lauer K, Midgard R, Minderhoud JM, Nyland H, Palffy G, Poser S, Aarli J. Early prognostic factors for disability in multiple sclerosis, a European multicenter study. Acta Neurol Scand 1992;85:212-8.

27 Gudmendsson KR. Clinical studies on multiple sclerosis in Iceland: a follow-up of previous survey and reappraisal. Acta Neurol Scand 1971;47(suppl 48):1-78.

28 Weinshenker BG, Rice GPA, Noseworthy JH, Carriere W, Baskerville J, Ebers GC. The natural history of multiple sclerosis: a geographically based study. III. Multivariate sclerosis: a geographically based study. III. Multivariate analysis of predictive factor
Brain 1991;114:1045-56.

29 Noseworthy JH, Paty DW, Wonnacott T, Feasby T, Ebers GC. Multiple sclerosis after age of 50 . Neurology 1983;33:1537-44

30 Poser S, Raun NE, Poser W. Age at onset, initial symptomatology and the course of multiple sclerosis. Acta Neurol Scand 1982;66:355-62.

31 Italian Multiple Sclerosis Study Group. Coordinating Center: G. Filippini. Prognostic value of the early clinical course in multiple sclerosis. 8th Congress of the ECTRIMS, 23-24 October 1992, Barcelona, Spain. Schweizer Archiv fur Neurologie und Psychiatrie 1993;144:327-8.

32 Larsson JP, Cavaale G, Reiise T, et al. Multiple sclerosis more than one disease. Acta Neurol Scand 1985; 72:145-50.

33 Olerup $\mathrm{O}$, Hillert J, Fredrikson S, et al. Primarily chronic progressive and relapsing/remitting multiple sclerosis:
two immunogenetically distinct disease entities. Proc Natl Acad Sci USA 1989;86:7113-7117.

34 Thompson AJ, Kermode AG, Wicks D, et al. Major differences in the dynamics of primary and secondary progresences in the dynamics of primary and secondary progr
sive multiple sclerosis. Ann Neurol 1991;29:53-62.

35 Thompson AJ, Hutchinson M, Brazil J, Feighery C, Martin EA. A clinical and laboratory study of benign multiple sclerosis. $Q \mathcal{F}$ Med 1986;58:69-80. 